\title{
Superação da Dormência de Sementes de Corda-De-Viola (Ipomoea quamoclit e I. hederifolia)
}

\author{
Overcoming Dormancy of Ipomoea quamoclit and I. hederifolia Seeds
}

\begin{abstract}
AZANIA, C.A.M. ${ }^{2}$, MARQUES, R.P. ${ }^{3}$, AZANIA, A.A.P.M. ${ }^{4}$ e ROLIM, J.C. ${ }^{5}$
RESUMO - Este estudo teve como objetivo testar o uso da água como método de superação de dormência de sementes de Ipomoea hederifolia e I. quamoclit (cordas-de-viola). Antes da realização dos tratamentos, as sementes das duas espécies foram submetidas ao teste de tetrazólio, para avaliar a sua viabilidade. Os tratamentos utilizados constituíram-se do uso de água quente em ponto de ebulição $\left(98^{\circ} \mathrm{C}\right)$ e em temperatura ambiente $\left(26^{\circ} \mathrm{C}\right)$, submetendose as sementes de ambas as espécies a diferentes períodos de exposição (zero; 0,$5 ; 1 ; 5 ; 10$; 15; 20; e 24 horas). A emergência das plântulas foi determinada diariamente, durante 21 dias, para posterior cálculo da porcentagem e da velocidade de emergência. As espécies de Ipomoea tiveram comportamento diferenciado. As sementes de I. hederifolia submetidas ao tratamento com água quente apresentaram maior porcentagem de emergência de plântulas que a da testemunha, a partir de 0,5 hora de embebição; os tratamentos mantidos em água à temperatura ambiente não foram eficientes para superar a dormência desta espécie. Para sementes de I. quamoclit, os tratamentos estudados não tiveram efeito na superação da dormência, sendo prejudiciais à sua qualidade.
\end{abstract}

Palavras-chave: dormência, sementes, plantas daninhas.

\begin{abstract}
An experiment was installed in Ribeirao Preto-SP to test the use of water as a method of overcoming dormancy of Ipomoea hederifolia and I. quamoclit seeds. Before carrying out the treatments, the seeds of the two species were submitted to tetrazolium test to assess their viability. The treatments consisted in submerging the seeds of both species in hot water at boiling point $\left(98^{\circ} \mathrm{C}\right)$ and in water at ambient temperature $\left(26^{\circ} \mathrm{C}\right)$, during different periods of exposure (null; 0, 5; 1; 5; 10; 15; 20 and 24 hours). Seedling emergence was determined daily, for 21 days, for posterior calculation of emergence speed rate and emergence speed. The Ipomoea species presented a differentiated behavior. The I. hederifolia seeds subjected to the hot water treatment showed a higher percentage of seedling emergence than the control, after 0.5 hours of soaking, and the cold water treatments were not efficient in overcoming dormancy of this species. For I. quamoclit seeds, the treatments applied had no dormancy overcome effect, damaging seed quality.
\end{abstract}

Keywords: dormancy, seeds, weeds

\section{INTRODUÇÃO}

As espécies de Ipomoea spp. pertencem à família Convolvulaceae e, no Brasil, são conhecidas como campainha e, principalmente, por corda-de-viola. Podem ser consideradas plantas ornamentais, visto a beleza e o colorido de suas flores, bem como infestantes em diversas culturas de grande importância econômica no País. Ipomoea quamoclit e Ipomoea hederifolia, assim como as outras espécies desse gênero, se reproduzem unicamente por meio de sementes (Kissmann \& Groth, 1999).

1 Recebido para publicação em 3.7.2007 e na forma revisada em 18.2.2009.

2 Pesquisador, Dr., Centro APTA de Cana do Instituto Agronômico de Campinas, Caixa Postal 206, 14001-970 Ribeirão Preto-SP, <azania@iac.sp.gov.br>; ${ }^{3}$ Graduanda em Engenharia Agronômica da Universidade Estadual de Mato Grosso do Sul e estagiária voluntária no Centro APTA de Cana do Instituto Agronômico de Campinas <renatinhaup@yahoo.com.br>; ${ }^{4}$ Pesquisadora Voluntária, Dra., Centro APTA de Cana do Instituto Agronômico de Campinas, <andrea.azania@hotmail.com>; ${ }^{5}$ Pesquisador Voluntário, Dr., Centro APTA de Cana do Instituto Agronômico de Campinas, <jcrolim@vivax.com.br>. 
Segundo esses autores, entre as inúmeras características das espécies de plantas da família Convolvulaceae, destaca-se a de produzirem um número considerável de sementes por planta, cerca de 50 a 300 . Atribui-se à dormência de suas sementes a causa dos diferentes fluxos de emergência de plantas de Ipomoea; suas sementes, após se desprenderem das plantas, entram em contato com o solo e somente um percentual delas germina prontamente; as demais vão germinando aleatoriamente, ao longo do tempo.

Essa característica dificulta o controle das diferentes espécies de Ipomoea, pois os herbicidas eficazes no controle dessas plantas daninhas possuem ação residual restrita, que, segundo Rodrigues \& Almeida (2005), dificilmente supera os 180 dias de persistência no solo. Devido a esse fato, os produtores precisam, dependendo do grau de infestação, intervir com o controle químico mais vezes durante o ciclo da cultura intervenções estas em que geralmente se utilizam herbicidas que deveriam possuir modos de ação diferentes, a fim de minimizar prováveis problemas com resistência de plantas daninhas aos herbicidas.

A dormência é o fenômeno em que as sementes de determinada espécie, mesmo sendo viáveis e possuindo todas as condições ambientais para iniciar o processo germinativo, não germinam. Sabe-se que a dormência de sementes de espécies de Ipomoea é causada pela impermeabilidade à água, cuja absorção é impedida pelo tegumento da semente, sendo necessária a efetivação de alguns tratamentos para que ocorra a embebição e, por consequência, o início do processo germinativo (Popinigis, 1985).

Os principais métodos empregados para superar a dormência de sementes consistem em tratamentos com ácido sulfúrico, envelhecimento das sementes, periodos de embebição em água, tratamento com compostos nitrogenados $\left(\mathrm{KNO}_{3}\right)$ e fito-hormônios (ácido giberélico) e fornecimento de luz e temperatura em quantidades adequadas (Voll et al., 2005).

A possibilidade de utilização de um método simples que, quando aplicado sobre as sementes de Ipomoea spp., seja capaz de minimizar o problema da dormência e resulte em estandes mais uniformes de plantas seria ideal aos estudos de manejo dessas espécies.

$\mathrm{Na}$ literatura existem diversas referências aos métodos de quebra de dormência das sementes (Mikusinski, 1987; Linhares et al., 2007; Pereira et al., 2007), a exemplo de Ogunwenmo \& Ugborogho (1999), que testando ácido sulfúrico concentrado, obtiveram $100 \%$ de germinação para I. obscura, I. aquatica e I. hederifolia. Por sua vez, Azania et al. (2003), testando ácido sulfúrico concentrado por 15 minutos no tratamento de sementes de I. quamoclit e I. hederifolia, obtiveram 66 e $82 \%$ de germinação, respectivamente.

Ocorre que substâncias abrasivas corroem muito as sementes pequenas, sendo desejáveis métodos menos abrasivos e práticos. Os métodos que envolvem água quente também proporcionaram resultados satisfatórios, conforme relatado por Azania et al. (2003), os quais recomendaram o estudo mais detalhado da água para superar a dormência das sementes de Ipomoea spp. Roversi et al. (2002), ao utilizarem água quente $\left(97^{\circ} \mathrm{C}\right)$ na superação de dormência de acácia-negra, concluíram ser um bom método de superação de dormência e que permitiu avaliar posteriormente o desempenho das sementes em testes conduzidos em viveiro.

Por outro lado, os experimentos para estudar a quebra de dormência de sementes geralmente são realizados em condições controladas de laboratório. É importante a realização de estudos em condições mais próximas daquelas do campo, que poderiam fornecer resultados mais próximos da realidade.

Este trabalho teve como objetivo avaliar o efeito da embebição em água na superação da dormência das sementes de duas espécies de Ipomoea.

\section{MATERIAL E MÉTODOS}

O trabalho foi desenvolvido no Centro de Cana do Instituto Agronômico de Campinas, localizado em Ribeirão Preto, Estado de São Paulo, em condições de campo. As 
espécies daninhas estudadas foram Ipomoea hederifolia e Ipomoea quamoclit, por serem as mais comuns nos canaviais paulistas. As sementes foram adquiridas na empresa especializada e procedeu-se ao teste do tetrazólio, para avaliação da viabilidade.

Para o teste de superação de dormência, foram utilizados béqueres de vidro, que acondicionaram as sementes. Em uma parte desses recipientes adicionou-se água à temperatura ambiente $\left(26^{\circ} \mathrm{C}\right)$, em quantidade suficiente para encobrir as sementes, e iniciou-se a contagem do tempo, a saber: $0 \mathrm{~h}$, $30 \mathrm{~min}, 1 \mathrm{~h}, 5 \mathrm{~h}, 10 \mathrm{~h}, 15 \mathrm{~h}, 20 \mathrm{~h}$ e $24 \mathrm{~h}$ de embebição, que se constituíram nos oito tratamentos estudados. Com o decorrer do tempo, as sementes eram retiradas e contadas em número de 100, para posterior semeadura. $\mathrm{Em}$ outros recipientes iguais foi utilizado o mesmo procedimento, porém com água quente $\left(98^{\circ} \mathrm{C}\right)$, colocada sobre as sementes; da mesma forma, procedeu-se à contagem dos tempos já mencionados.

As sementes foram semeadas em número de 100 em bandejas de isopor (13 x $15 \times 5 \mathrm{~cm})$, preenchidas com substrato tipo Plantmax, e cada bandeja constituía uma repetição (parcela) do tratamento. A semeadura foi realizada em 2/10/2006, e as bandejas, colocadas em viveiro de mudas.

O delineamento experimental utilizado foi o inteiramente casualizado, com oito tratamentos (0 h, 30 min, 1 h, 5 h, 10 h, 15 h, 20 h e $24 \mathrm{~h}$ de embebição) e cinco repetições, com 100 sementes por repetição, para as condições de água fria $\left(26^{\circ} \mathrm{C}\right)$ e quente $\left(98^{\circ} \mathrm{C}\right)$ e para cada uma das espécies de plantas daninhas (I. hederifolia e I. quamoclit). As bandejas, após a semeadura, foram colocadas sobre céu aberto (viveiro de mudas), sem proteção contra as intempéries climáticas, recebendo uma única irrigação diária; a quantidade de água colocada nessa irrigação foi suficiente apenas para manter o substrato das bandejas úmido e garantir a emergência das plântulas.

A emergência das plântulas foi determinada diariamente, durante 21 dias, para posterior cálculo da porcentagem e da velocidade de emergência (Maguire, 1962). $O$ percentual de emergência foi calculado utilizando-se da equação $x=\left(100^{*} n_{1}\right) / n_{2}$, sendo $n_{1}=$ número de plântulas final e $n_{2}=$ número de sementes semeadas, a partir do número de plântulas emergidas aos 21 dias após semeadura (DAS).

A análise de variância (teste $F$ ) foi efetuada e, posteriormente, para comparação das médias dos tratamentos, utilizou-se o teste de Tukey a $5 \%$ de probabilidade. Os dados de porcentagem foram transformados em $\sqrt{x+0,5}$.

\section{RESULTADOS E DISCUSSÃO}

Pelo teste de tetrazólio, 89 e 92\% das sementes estavam viáveis, para Ipomoea quamoclit e I. hederifolia, respectivamente.

As espécies de Ipomoea estudadas tiveram comportamento diferenciado em relação às variáveis analisadas, de acordo com os tratamentos a que foram submetidas.

Observam-se, nas Tabelas 1 e 2, os valores da porcentagem de emergência, do índice de velocidade de emergência e da velocidade de emergência das plântulas das espécies estudadas, nas condições de água quente e fria e nos diversos tratamentos de tempo a que foram expostas as sementes.

Assim, sementes de Ipomoea hederifolia (Tabela 1) submetidas ao tratamento com água quente apresentaram, aos 21 dias após a semeadura, maior porcentagem de emergência de plântulas do que a testemunha, a partir de $0,5 \mathrm{~h}$ de manutenção das sementes em água quente. Esses resultados corroboram as informações de Popinigis (1985), de que a germinação será tanto mais rápida e o processo mais eficiente quanto maior for a temperatura, até certo limite, podendo esta variar de acordo com a espécie. Os tratamentos com água fria não serviram para quebrar a dormência desta espécie. Os dados para índice de velocidade de emergência para esta espécie, nos tratamentos mantidos em água quente, confirmam os dados obtidos para porcentagem de germinação, indicando a existência de maior vigor nas sementes tratadas com água quente. Quando se analisam os dados de velocidade de emergência, pode-se concluir que, teoricamente, lotes de sementes de $I$. hederifolia germinariam e emergiriam do solo mais rapidamente 
se fossem submetidas a tratamento com água quente. De qualquer forma, somente a água quente é que proporcionou a superação da dormência das sementes de I. hederifolia.

Quando se observa o comportamento das sementes de Ipomoea hederifolia tratadas com água quente, pode-se perceber que os tratamentos com 1, 5 e 10 horas foram os mais eficientes, destacando aquele em que as sementes foram submetidas a uma hora na água quente $(65,2 \%)$.

As sementes de Ipomoea quamoclit (Tabela 2) podem ter sido tolerantes à elevação da temperatura, não havendo superação de dormência de suas sementes apenas com tratamentos à base de água quente $\left(98^{\circ} \mathrm{C}\right)$.

Tabela 1 - Porcentagem de emergência, índice de velocidade de emergência (IVE) e velocidade de emergência (VE) de plântulas de Ipomoea hederifolia obtidas em 21 dias após semeadura, após tratamentos das sementes em água quente e fria. Ribeirão Preto-SP. 2006

\begin{tabular}{|c|c|c|c|}
\hline Tratamento & \multirow{2}{*}{$\begin{array}{l}\text { Emergên - } \\
\text { cia }(\%)^{1 /}\end{array}$} & \multirow{2}{*}{ IVE } & \multirow{2}{*}{$\mathrm{VE}$} \\
\hline Água quente & & & \\
\hline Testemunha & $4,90 \mathrm{c}$ & $5,16 d$ & $6,92 a$ \\
\hline 0,5 hora & $7,50 a$ & $14,09 a b c$ & $5,47 b$ \\
\hline 1 hora & $8,09 a$ & $19,42 a$ & $4,70 \mathrm{~b}$ \\
\hline 5 horas & $7,95 a$ & $14,46 a b c$ & $5,56 b$ \\
\hline 10 horas & $7,92 a$ & $15,91 a b$ & $5,23 b$ \\
\hline 15 horas & $6,33 b$ & $9,14 c d$ & $5,52 b$ \\
\hline 20 horas & $7,15 a b$ & $13,60 b c$ & $4,78 b$ \\
\hline 24 horas & $7,43 a$ & $14,44 a b c$ & $5,65 b$ \\
\hline$F$ & $19,52 * *$ & $11,09 * *$ & $6,64 * *$ \\
\hline d.m.s. (Tukey, 5\%) & 1,04 & 5,59 & 1,21 \\
\hline $\mathrm{CV}(\%)$ & 7,59 & 21,89 & 10,81 \\
\hline Tratamento & \multirow{2}{*}{$\begin{array}{l}\text { Emergên - } \\
\text { cia }(\%)^{\frac{1}{}}\end{array}$} & \multirow{2}{*}{ IVE } & \multirow{2}{*}{$\mathrm{VE}$} \\
\hline Água fria & & & \\
\hline Testemunha & $3,69 b c$ & $3,03 a b$ & 6,09 \\
\hline 0,5 hora & $4,67 a b$ & $4,24 a b$ & 6,62 \\
\hline 1 hora & $4,15 a b c$ & $3,31 \mathrm{ab}$ & 6,87 \\
\hline 5 horas & $3,95 a b c$ & $3,40 a b$ & 6,19 \\
\hline 10 horas & $4,90 a$ & $4,72 a b$ & 7,65 \\
\hline 15 horas & $4,29 a b c$ & $4,86 a$ & 5,86 \\
\hline 20 horas & $3,90 a b c$ & $2,77 a b$ & 8,11 \\
\hline 24 horas & $3,41 c$ & $2,37 b$ & 6,86 \\
\hline $\mathrm{F}$ & $3,75 * *$ & $3,19 *$ & 1,24 \\
\hline d.m.s. (Tukey, 5\%) & 1,10 & 2,36 & 3,20 \\
\hline $\mathrm{CV}(\%)$ & 13,84 & 32,07 & 23,06 \\
\hline
\end{tabular}

1/ para análise estatística, os dados foram transformados em raiz de $\mathrm{x}+0,5 . *$ significativo a $5 \%$ de probabilidade; $* *$ significativo a $1 \%$ de probabilidade.
Entretanto, como os resultados da porcentagem de emergência foram inferiores aos da testemunha, poderia ser um indicativo de que a própria temperatura possa ter inviabilizado as sementes, uma vez que o índice de velocidade de emergência foi maior para a testemunha e diferiu dos demais tratamentos, e a velocidade de emergência também foi menor, indicando que as plantas não embebidas em água quente levaram menos dias para emergirem. Com isso, os tratamentos estudados não tiveram efeito na superação da dormência, sendo prejudiciais à sua qualidade.

Deve-se lembrar que, segundo Ferreira et al. (2004), o mecanismo de atuação da água quente para superar a dormência de sementes ainda não é bem conhecido.

Tabela 2 - Porcentagem de emergência, índice de velocidade de emergência (IVE) e velocidade de emergência (VE) de plântulas de Ipomoea quamoclit obtidas em 21 dias após semeadura, após tratamentos das sementes em água quente e fria. Ribeirão Preto-SP. 2006

\begin{tabular}{|c|c|c|c|}
\hline Tratamento & \multirow{2}{*}{$\begin{array}{l}\text { Emergên - } \\
\text { cia }(\%)^{1 /}\end{array}$} & \multirow{2}{*}{ IVE } & \multirow{2}{*}{ VE } \\
\hline Água quente & & & \\
\hline Testemun ha & $6,56 a$ & $9,59 a$ & 5,19 \\
\hline 0,5 hora & $4,12 b c$ & $3,16 b c d$ & 6,24 \\
\hline 1 hora & $4,12 b c$ & $2,82 \mathrm{bcd}$ & 6,94 \\
\hline 5 horas & $4,64 b$ & $3,93 b c$ & 6,49 \\
\hline 10 horas & $4,49 b$ & $3,67 b c$ & 6,41 \\
\hline 15 horas & $2,67 d$ & $1,08 d$ & 7,61 \\
\hline 20 horas & $3,22 \mathrm{~cd}$ & $1,59 \mathrm{~cd}$ & 7,14 \\
\hline 24 horas & $4,77 b$ & $4,48 b$ & 6,12 \\
\hline $\mathrm{F}$ & $16,13 * *$ & $19,07 * *$ & 2,21 \\
\hline d.m.s. (Tukey, 5\%) & 1,24 & 2,57 & 2,12 \\
\hline $\mathrm{CV}(\%)$ & 14,92 & 35,29 & 16,90 \\
\hline Tratamento & \multirow{2}{*}{$\begin{array}{l}\text { Emergên - } \\
\text { cia }(\%)^{1 /}\end{array}$} & \multirow{2}{*}{ IVE } & \multirow{2}{*}{$\mathrm{VE}$} \\
\hline Água fria & & & \\
\hline Testemunha & 5,58 & $6,32 b$ & 5,13 \\
\hline 0,5 hora & 5,57 & $6,81 a b$ & 5,31 \\
\hline 1 hora & 6,00 & $7,34 a b$ & 5,55 \\
\hline 5 horas & 6,08 & $8,55 a b$ & 5,01 \\
\hline 10 horas & 5,92 & $7,77 a b$ & 5,15 \\
\hline 15 horas & 6,72 & $11,20 a$ & 4,64 \\
\hline 20 horas & 6,16 & $9,96 a b$ & 4,42 \\
\hline 24 horas & 5,49 & $6,63 a b$ & 5,32 \\
\hline $\mathrm{F}$ & 1,88 & $2,65 *$ & 1,14 \\
\hline d.m.s. (Tukey, $5 \%$ ) & 1,27 & 4,57 & 1,50 \\
\hline $\mathrm{CV}(\%)$ & 11,15 & 29,41 & 15,39 \\
\hline
\end{tabular}

1/ para análise estatística, os dados foram transformados em raiz de $\mathrm{x}+0,5 . *$ significativo a $5 \%$ de probabilidade; $* *$ significativo a $1 \%$ de probabilidade. 
Azania et al. (2003) conseguiram resultados satisfatórios tratando sementes dessa espécie com calor seco, obtendo uma taxa de germinação de $70 \%$.

Em estudos realizados por Voll et al. (2003) com I. grandifolia tratada com água fria $\left(20{ }^{\circ} \mathrm{C}\right)$, os níveis de germinação se mantiveram constantes nos períodos de embebição entre 6 e 48 horas; embora os acréscimos de absorção de água fossem significativos, a germinação encerrou-se aos 14 dias. Além disso, esses autores constataram que a taxa de germinação dessa espécie foi menor em relação a outras sementes coletadas da mesma espécie, não progredindo com maiores períodos de embebição.

Esses resultados são confirmados por Ferreira et al. (2004), os quais constataram que a existência de diferenças na germinação e na emergência de plântulas é comum, inclusive em sementes da mesma espécie.

O comportamento das sementes de I. hederifolia diante dos tratamentos a que foram submetidas pode esclarecer o motivo pelo qual há aumento na emergência dessa espécie nas lavouras do Brasil nos meses de verão, provavelmente devido às condições de calor e umidade, que lhe são favoráveis.

As espécies de Ipomoea estudadas neste trabalho tiveram comportamento diferenciado. Assim, as sementes de I. hederifolia submetidas ao tratamento com água quente apresentaram maior porcentagem de emergência de plântulas do que a testemunha, a partir de 0,5 hora de manutenção das sementes em água quente; os tratamentos mantidos em água fria não serviram para superar a dormência desta espécie. I. quamoclit não sofreu interferência marcante dos tratamentos efetuados, não havendo superação de dormência de suas sementes apenas com tratamentos à base de água fria, e na água quente pode ter ocorrido morte das sementes, pois a porcentagem de emergência em relação à testemunha foi reduzida.

\section{LITERATURA CITADA}

AZANIA, A. A. P. M. et al. Métodos de superação de dormência em sementes de Ipomoea e Merremia. Planta Daninha, v. 21, n. 2, p. 203-209, 2003.

FERREIRA, R. A.; DAVIDE, A. C.; MOTTA, M. S. Vigor e viabilidade de sementes de Senna multijuga (Rich.) Irwin et Barn. e Senna macranthera (Collad.) Irwin et Barn.; num banco de sementes em solo de viveiro. R. Bras. Sementes, v. 26, n. 1, p. 24-31, 2004.

KISSMANN, K. G.; GROTH, D. Convolvulaceae Juss. In: KISSMANN, K. G.; GROTH, D. Plantas infestantes e nocivas. 2.ed. São Paulo: BASF Brasileira, 1999. p. 673-693.

LINHARES, P. C. et al. Métodos de superação de dormência em sementes de jitirana. R. Caatinga, v. 20, n. 4, p. 61-67, 2007.

MAGUIRE, J. D. Speed of germination-aid in selection and evaluation for seedling emergence and vigor. Crop Sci., v. 2, n. 1, p. 176-177, 1962.

MIKUSINSKI, O. M. Testes de embebição e germinação em sementes de Ipomoea aristolochiaefolia. R. Bras. Sementes, v. 9, n. 3, p. 103-108, 1987.

OGUNWENMO, K.; UGBOROGHO, R. E. Effects of chemical and mechanical scarification on seed germination of five species of Ipomoea (Convolvulaceae). B. Soc.

Broteriana, v. 69, p. 147-162, 1999.

PEREIRA, E. W. L. et al. Superação de dormência em sementes de jitirana (Merremia aegyptia L.). R. Caatinga, v. 20, n. 4 , p. 61-67, 2007.

POPINIGIS, F. Fisiologia da semente. Brasília: AGIPLAN, 1985. $289 \mathrm{p}$.

RODRIGUES, B. N.; ALMEIDA, F. S. Guia de herbicidas. 5.ed. Londrina: Edição dos Autores, 2005. 592 p.

ROVERSI, T. et al. Superação de dormência em sementes de acácia negra (Acacia mearnsii Willd.). R. Bras. Agroci., v. 8, n. 2, p. 161-163, 2002.

VOLL, E. et al. Relações entre germinação de sementes de espécies de plantas daninhas e uso da condutividade elétrica. Planta Daninha, v. 21, n. 2, p. 181-189, 2003.

VOLL, E. et al. Dinâmica das plantas daninhas e práticas de manejo. Londrina: Embrapa Soja, 2005. 85 p.

(Documentos, 60). 